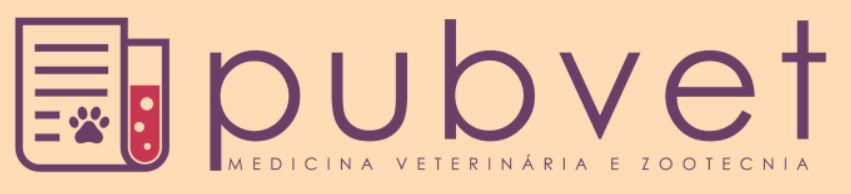

https://doi.org/10.22256/pubvet.v12n3a46.1-5

\title{
Farmacodermia em cão da raça Dálmata: Relato de caso
}

\author{
Claudio Douglas de Oliveira Guimarães ${ }^{\bullet}{ }^{*}$, Caio Vitor Cavalcante de Carvalho ${ }^{\bullet}$, Ene \\ Madeira de Oliveira Aires ${ }^{\bullet}$, Mário José Costa Carneiro ${ }^{\bullet}$, Maridelzira Betânia \\ Moraes David ${ }^{1}$, Luiz Fernando Moraes Moreira ${ }^{\bullet}$
}

${ }^{1}$ Hospital Veterinário Mário Dias Teixeira - HOVET da Universidade Federal Rural da Amazônia - UFRA, Belém Pará, Brasil.

*Autor para correspondência. E-mail: cdoguimaraes@gmail.com

\begin{abstract}
RESUMO. Entende-se como farmacodermia a reação de hipersensibilidade a determinados fármacos manifestada por lesões dermatológicas focais ou difusas. Este trabalho apresenta um caso de farmacodermia em cão após administração de amoxicilina associada à clavulanato de potássio. Foi atendido no Hospital Veterinário Professor Mário Dias Teixeira da Universidade Federal Rural da Amazônia um cão macho, dálmata, com um ano e cinco meses de idade, pesando $33 \mathrm{~kg}$ tendo como queixa principal a presença de constipação há dois meses. A partir de exame clínico e exames de imagem foi observado que o paciente apresentava estreitamento da ampola retal, cistos prostáticos e cistite, sendo recomendadas anoplastia e orquiectomia terapêuticas. Foi instituído para o pré e pósoperatório cloridrato de tramadol, meloxican e amoxicilina associada à clavulanato de potássio por via oral, sendo observado no nono dia pós-cirúrgico a presença de lesões descamativas na pele, concentradas principalmente em região dorso-lombar, com sinais de infecção bacteriana secundária. O meloxican foi substituído por cetoprofeno e o tratamento com amoxicilina com clavulanato foi mantido por mais cinco dias. Após esse período, o paciente retornou apresentando evolução das lesões, emagrecimento e hipofagia. Devido à evolução do caso, história clinica e apresentação das lesões, suspeitou-se de farmacodermia. Posteriormente, foi feita substituição da amoxicilina por ciprofloxacino e debridamento cirúrgico das lesões. Finalmente, após o tratamento clínico cirúrgico, observou-se regressão das lesões com bom processo de cicatrização, o que sugere que o caso possa ser uma reação farmacológica à amoxicilina.
\end{abstract}

Palavras chave: dermatologia, farmacologia, intoxicação

\section{Pharmacodermia in a dog of the Dalmatian breed: Case report}

ABSTRACT. It is understood as pharmacodermia the hypersensitivity reaction to certain drugs manifested by focal or diffuse dermatological lesions. This paper presents a case of pharmacodermia in dogs after administration of amoxicillin associated with potassium clavulanate. A Dalmatian dog, male, one year and five months old, weighing $33 \mathrm{~kg}$ was attended at the Veterinary Hospital Professor Mário Dias Teixeira of the Federal Rural University of the Amazon, having as main complaint the presence of constipation about two months ago. From clinical examination and imaging studies it was observed that the patient had narrowing of the rectal ampulla, prostatic cysts and cystitis, and therapeutic anoplasty and orchiectomy were recommended. Tramadol hydrochloride, meloxicam, and amoxicillin associated with potassium clavulanate were instituted for the pre and postoperative period. The presence of scaly lesions on the skin and signs of secondary bacterial infection, mainly concentrated in the lumbar region, was observed on the ninth postoperative day. Meloxicam was replaced by ketoprofen and treatment with amoxicillin and clavulanate was maintained for another five days. After this period, the patient returned 
with lesion evolution, emaciation and hypophagia. Due to the evolution of the case, clinical history and presentation of the lesions, pharmacodermia was suspected. Subsequently, amoxycillin was replaced with ciprofloxacin and surgical debridement of the lesions. Finally, after surgical treatment, regression of lesions with a good healing process was observed, suggesting that the case may be a pharmacological.

Keywords: dermatology, farmacology, intoxication

\section{Farmacodermia en perro de la raza Dálmata: Reporte deun caso}

RESUMEN. Se entiende como farmacodermia la reacción de hipersensibilidad a determinados fármacos manifestada por lesiones dermatológicas focales o difusas. Este trabajo presenta un caso de farmacodermia en un perro tras la administración de amoxicilina asociada a clavulanato de potasio. Fue atendido en el Hospital Veterinario Profesor Mário Dias Teixeira de la Universidad Federal Rural de la Amazonía un perro macho, dálmata, con un año y cinco meses de edad, pesando $33 \mathrm{~kg}$ y teniendo como queja principal la presencia de constipación desde hace dos meses. A partir del examen clínico y exámenes de imagen se observó que el paciente presentaba estrechamiento de la ampolla rectal, quistes prostáticos y cistitis, siendo recomendadas anoplastia y orquiectomía terapéuticas. Se estableció para el pre y post-operatorio hidrocloruro de tramadol, meloxican y amoxicilina asociada a la clavulanato de potasio por vía oral, siendo observado en el noveno día post-quirúrgico la presencia de lesiones descamativas en la piel, concentradas principalmente en región dorso-lumbar y signos de infección bacteriana secundaria. El meloxican fue sustituido por cetoprofeno y el tratamiento con amoxicilina con clavulanato fue mantenido por otros cinco días. Después de ese período, el paciente retornó presentando evolución de las lesiones, adelgazamiento e hipofagia. Debido a la evolución del caso, la historia clínica y la presentación de las lesiones, se sospechó de la farmacodermia. Posteriormente, se hizo sustitución de la amoxicilina por ciprofloxacino y debridamiento quirúrgico de las lesiones. Finalmente, después del tratamiento clínico quirúrgico, se observó regresión de las lesiones con buen proceso de cicatrización, lo que sugiere que el caso puede ser una reacción farmacológica a la amoxicilina.

Palabras clave: dermatología, farmacología, intoxicación

\section{Introdução}

Farmacodermia consiste em uma reação adversa a fármacos que se manifesta na pele, mucosas, anexos e em outros sistemas, sendo conhecida também como erupção por fármaco, reação cutânea medicamentosa, toxidermia, dermatose medicamentosa ou dermatite medicamentosa. É uma doença mucocutânea, pleomórfica, de natureza recidivante, variavelmente pruriginosa e algumas vezes acompanhada por sinais sistêmicos, cujas lesões cutâneas são de tipos e configurações variáveis (Larsson, 1996, Caballero et al., 2004, Aldama et al., 2009).

Pode-se considerar que esta patologia consiste em um quadro de hipersensibilidade cutânea resultante da administração de um fármaco, sendo considerada rara em animais da espécie canina (Sousa et al., 2005). Entretanto, um fator que pode contribuir para o desenvolvimento e a frequência dessas alterações na medicina veterinária é o crescente lançamento de drogas pela indústria farmacêutica, associado ao uso indiscriminado das terapias (Giachetto et al., 2008). O diagnóstico de farmacodermia pode ser difícil pelo fato de as características da erupção cutânea serem similares à de outras doenças de pele (Nayak \& Acharjya, 2008) e também porque, em muitos casos, o paciente é exposto a mais de um fármaco simultaneamente (Festa Neto et al., 1990, Nayak \& Acharjya, 2008). Sendo assim, este trabalho tem como objetivo relatar a ocorrência de farmacodermia em um cão dálmata após administração oral de um antibiótico da classe das penicilinas.

\section{Relato de caso}

Um cão macho da raça Dálmata de um ano e cinco meses de idade, pesando $33 \mathrm{~kg}$ foi atendido no Hospital Veterinário Professor Mário Dias Teixeira, na Universidade Federal Rural da Amazônia no dia 20 de janeiro de 2017. Na 
sequência, foi encaminhado para o setor de Clínica Cirúrgica, tendo como principal queixa a presença de constipação há aproximadamente dois meses. $\mathrm{O}$ tutor relatou que o canino apresentava inquietação no momento em que tentava defecar, por vezes vocalizando e liberando pequenos bolos fecais de consistência firme e aspecto ressecado. Durante a anamnese foi identificado que o animal apresentava anorexia, normodipsia, disquezia e normúria. Ao exame clínico, os parâmetros fisiológicos estavam dentro da normalidade, sendo observado abaulamento em região abdominal com discreta sensibilidade dolorosa à palpação. Ao toque retal, foi observado estreitamento da ampola retal e considerável acúmulo de fezes em porção final do reto. Posteriormente, foram realizados exames complementares, tais como: hemograma, bioquímica sérica (ureia, creatinina, alanina aminotransferase, fosfatase alcalina, proteínas totais e frações), ultrassonografia abdominal e eletrocardiograma. $\mathrm{O}$ hemograma demonstrou leucocitose $\left(20.300 \mathrm{cel} / \mathrm{mm}^{3}\right)$, e a radiografia evidenciou a presença de estômago e alças intestinais distendidos por conteúdo gasoso, cólon ascendente, transverso e descendente apresentando dilatação por conteúdo fecal com intenso deslocamento desse segmento para a direita e bexiga repleta. O ultrassom registrou suspeita de cistite crônica associada a cistos prostáticos. Mediante o quadro clínico e resultados dos exames complementares, o animal foi submetido à anoplastia e orquiectomia terapêuticas de acordo com técnica cirúrgica descrita por Fossum (2014), sendo prescrito como mediações pré-operatórias amoxicilina associada à clavulanato de potássio na dose de $20 \mathrm{mg} / \mathrm{kg}$ por sete dias, meloxican na dose de $0,2 \mathrm{mg} / \mathrm{kg}$ e cloridrato de tramadol na dose de $4 \mathrm{mg} / \mathrm{kg}$ por quatro dias antes da cirurgia, todos sendo administrados por via oral.

Após 48 horas o animal retornou para reavaliação, na qual foi observada boa cicatrização da ferida operatória, sem sinais de inflamação e infecção. O proprietário relatou que o paciente já estava se alimentando melhor e defecando fezes pastosas; porém, sem sinais de dor.

No nono dia pós-cirúrgico, um dia antes do recomendado para retirada dos pontos, o animal retornou precocemente para atendimento, pois apresentou lesões descamativas na pele, concentradas principalmente em região dorsolombar, com sinais de infecção bacteriana secundária (Figura 1). As lesões apresentavam-se exsudativas, eritematosas, de fácil desprendimento da pele, semelhante à lesão por queimadura. Foi suspensa a terapia antiinflamatória com meloxican e substituída por cetoprofeno na dose de $1 \mathrm{mg} / \mathrm{kg}$ por cinco dias, por via oral, mantida a terapia antibiótica com amoxicilina associada à clavulanato de potássio e adicionada terapia tópica com pomada contendo colagenase e cloranfenicol por cinco dias. $\mathrm{O}$ animal retornou após cinco dias apresentando piora das lesões, emagrecimento e hipofagia. Devido às características da lesão, história clínica e pesquisa bibliográfica, o caso foi considerado como possível reação adversa ao uso da amoxicilina, caracterizando um quadro de farmacodermia. Dessa forma, a administração do antibiótico foi suspensa e o paciente foi submetido à cirurgia para debridamento e limpeza das lesões de pele (Figura 2).

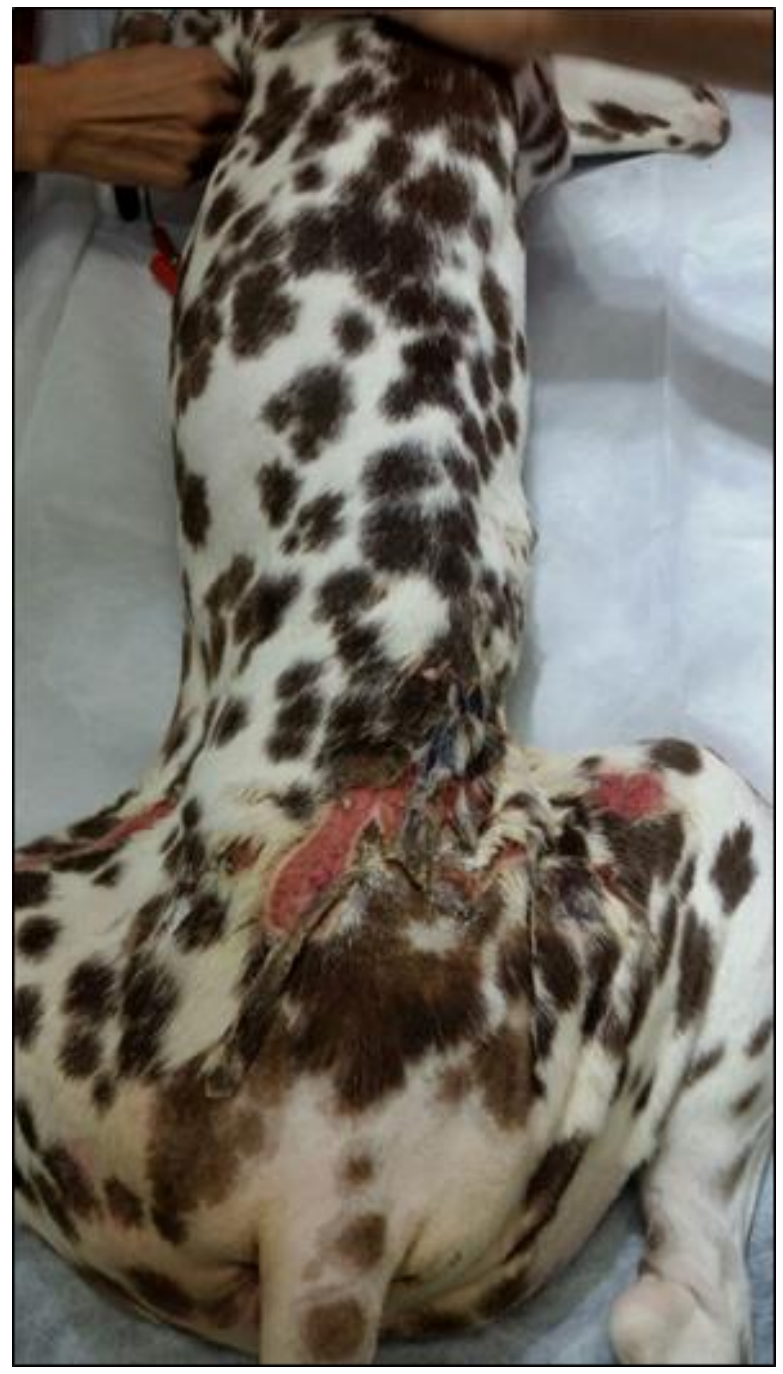

Figura 1. Paciente apresentando lesões descamativas, exsudativas e de fácil desprendimento. 


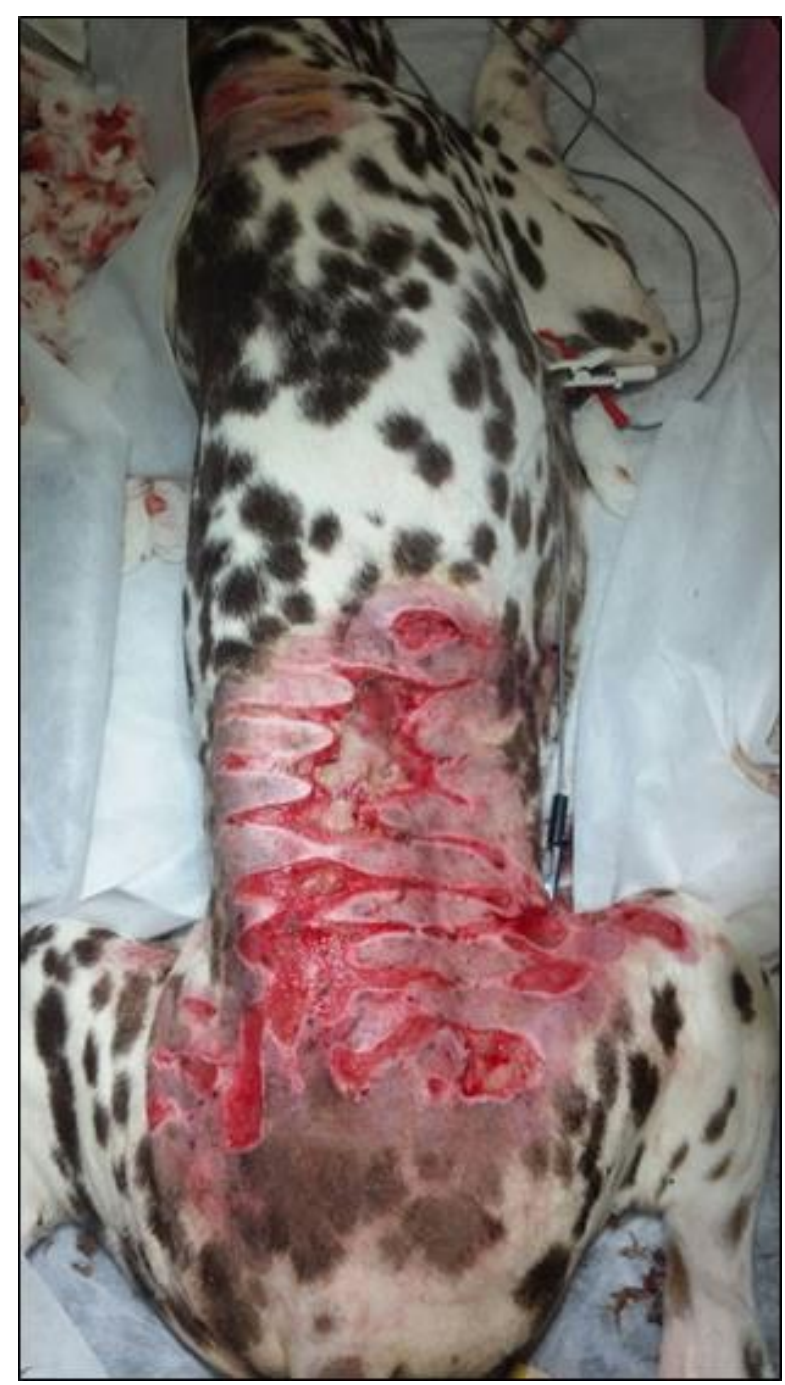

Figura 2. Paciente após a realização do debridamento cirúrgico.

\section{Discussão}

Neste trabalho, assim como em muitos casos de farmacodermia, o diagnóstico foi tardio, pois como afirma Larsson (1996), Caballero et al. (2004), Nayak \& Acharjya (2008) devido à grande variedade de apresentações clínicas, ao fato de as características da erupção cutânea serem similares às de outras doenças de pele e também porque, muitas vezes, o paciente é exposto a mais de um fármaco simultaneamente, o diagnóstico da reação pode ser difícil. Pelo fato de inicialmente suspeitar-se de reação a um dos fármacos utilizados, optou-se pela supressão dos medicamentos, de forma a detectar a substância responsável, como sugerido por Pérez \& Yabor (2001), Nayak \& Acharjya (2008). Ainda quanto ao diagnóstico da patologia, como não existe um método simples, de fácil acesso e específico em medicina veterinária para identificar o fármaco agressor, a forma mais prática de identificar o agente etiológico é expondo o paciente novamente ao medicamento e observando o que se sucede. Porém, repetir a administração do fármaco, processo conhecido por "desafio farmacológico" é um método contraindicado em razão do risco que pode gerar para o paciente, podendo resultar inclusive em óbito (Festa Neto et al., 1990, Nayak \& Acharjya, 2008, Silvares et al., 2008).

A amoxicilina é classificada como um antibiótico da classe das penicilinas semissintéticas que, junto com o clavulanato de potássio, tem seu efeito potencializado pela inibição da betalactamase, fazendo com que os micro-organismos tornem-se sensíveis à rápida ação bactericida do antimicrobiano (Guardabassi et al., 2009). Reconhecidamente utilizada na medicina veterinária (Matos et al., 2012, Gouvea et al., 2012), já existem relatos de reações farmacodérmicas após sua administração, a exemplo dos relatos de Posani et al. (2017), os quais descreveram dois casos de farmacodermia após o uso de amoxicilina associado à clavulanato para o tratamento de piodermite em dois caninos que apresentaram lesões pustulares e eritematosas, melhorando após supressão da medicação. Vale ressaltar que, na maioria dos trabalhos disponíveis na literatura, não há detalhamento quanto ao fabricante e/ou laboratório responsável pela droga que desencadeou a reação, sendo difícil saber se o medicamento usado provém de laboratório veterinário ou não. Essa informação seria imprescindível para identificar possíveis relações dos quadros clínicos com a procedência do fármaco.

Em nosso estudo, as lesões estão de acordo com as descritas por Silva \& Roselino (2003), as quais podem se apresentar como necrólise epidérmica tóxica, caracterizada por necrose das células epiteliais, o que ocasiona o deslocamento epidérmico, resultando em aparência similar àquelas lesões provocadas por queimaduras. No entanto, estes mesmos autores relatam que a farmacodermia pode-se manifestar com lesões sob vários aspectos, tais como dermite esfoliativa, urticária, dermatite vesiculobolhosa, angioedema, eczema e penfigóide bolhoso.

De acordo com a anamnese e o desenvolvimento das lesões dermatológicas, o caso de farmacodermia relatado pode ser classificado como sendo de origem imunológica, pois o paciente desenvolveu a doença após uma segunda exposição ao medicamento que, neste caso, foi a amoxicilina, um antibiótico pertencente à classe das penicilinas. Esta classificação baseia- 
se nas descrições de Nelson \& Couto (2015), os quais caracterizam este tipo de reação adversa como sendo de origem imunológica ou nãoimunológica, de acordo com a história e aspecto clínico do quadro.

\section{Conclusões}

A história clínica do paciente associada à conduta terapêutica adotada neste caso demonstra a evolução e recrudescimento de lesões cutâneas com o uso da amoxicilina associada ao clavulanato de potássio, sendo observada regressão das feridas após supressão desse antibiótico, caracterizando um quadro de farmacodermia. Enfatiza-se que o sucesso no tratamento se deu, principalmente, pela precoce suspeita diagnóstica, permitindo boa evolução do caso.

\section{Agradecimentos}

À equipe de veterinários residentes e técnicos do Hospital Veterinário da Universidade Federal Rural da Amazônia pelo apoio durante o tratamento do paciente.

\section{Referências Bibliográficas}

Aldama, A., Gorostiaga, G., Rivelli, V. \& Mendoza, G. 2009. Formas graves y mortales de las farmacodermias. A propósito de 53 casos. Dermatologia $C M Q, 4,22-26$.

Caballero, A. B. A., Rivelli, V. B. \& Gorostiaga, G. 2004. Farmacodermias em niños. Pedíatria, 31, 112-116.

Festa Neto, C., Forlani, L. X. R., Haddad, E. S. \& Souza, P. K. 1990. Farmacodermia: aspectos epidemiológicos, tipos clínicos e agentes causais. Anais Brasileiro de Dermatologia, 65, 125-8.

Fossum, T. W. 2014. Cirurgia de pequenos animais, 4 edn. Elsevier Brasil, São Paulo.

Giachetto, G., Danza, Á., Lucas, L., Cristiani, F., Cuñetti, L., Vázquez, X. \& Greczanik, A. 2008. Hospitalizaciones por reacciones adversas a medicamentos y abandono del tratamiento farmacológico en el hospital universitario. Revista Médica del Uruguay, 24, 102-108.

Gouvea, A. S., Aguiar, J., Mucillo, M., Stedile, R., Yamazaki, P. H., Gonzalez, P. C., Velasque, A.
G., Alievi, M. M. \& Beck, C. A. C. 2012. Tracheal foreign body in dog. Arquivo Brasileiro de Medicina Veterinária $e$ Zootecnia, 64, 759-762.

Guardabassi, L., Jensen, L. B. \& Kruse, H. 2009. Guia de antimicrobianos em veterinária. Artmed Editora, Porto Alegre.

Larsson, C. E. 1996. Dermatopatias alérgicashipersensibilidade medicamentosa (HM). Clínica Veterinária, 5, 351-355.

Matos, C. B., Madrid, I. M., Santin, R., Azambuja, R. H., Schuch, I., Meireles, M. C. A. \& Cleff, M. B. 2012. Multifactorial dermatitis in a dog. Arquivo Brasileiro de Medicina Veterinária e Zootecnia, 64, 1478-1482.

Nayak, S. \& Acharjya, B. 2008. Adverse cutaneous drug reaction. Indian Journal of Dermatology, 53, 2-8.

Nelson, R. W. \& Couto, C. G. 2015. Medicina interna de pequenos animais. Elsevier Editora, Amsterdan.

Pérez, O. P. \& Yabor, V. A. 2001. Necrólisis epidérmica tóxica: descripción de 1 caso. Revista Cubana de Pediatría, 73, 245-248.

Posani, M. Y. H., Paludetti, M., Pereira, C. S., Galati, L. H. H. \& Brunetto, M. A. 2017. Drug reaction caudes by clavulanate amoxicillin in dog: Report of two dogs. MOJ Toxicology, 6, 00066.

Silva, L. M. \& Roselino, A. M. F. 2003. Reações de hipersensibilidade a drogas (farmacodermia). Medicina, 36, 460-471.

Silvares, M. R. C., Abbade, L. P. F., Lavezzo, M., Gonçalves, T. M. \& Abbade, J. F. 2008. Skin reactions to drugs. Anais Brasileiros de Dermatologia, 83, 227-232.

Sousa, M. G., Talieri, I. C., Jorge, A. T. B. \& Costa, M. T. 2005. Reação farmacodérmica decorrente do uso do levamisol: relato de caso. Arquivo Brasileiro de Medicina Veterinária e Zootecnia, 57, 154-157.

Article History:

Received 11 November 2017

Accepted 15 December 2017

Available online 10 February 201

License information: This is an open-access article distributed under the terms of the Creative Commons Attribution License 4.0, which permits unrestricted use, distribution, and reproduction in any medium, provided the original work is properly cited. 